\title{
Consumer Preference Implications on Onion Suppliers
}

\section{Nadia Hassan Sidahmed Hassan*}

Industrial Research and Consultancy Centre, Khartoum, Sudan

\begin{abstract}
This paper introduces finding and results of an explorative research on consumer preference for onion products. Research is concerned with investigating whether user households' demand for processed onion is influenced by attributes that they conceive for the product and whether users can identify these attributes. Such attributes are presumed to be attended to by manufacturer. The study had been designed with the purpose to firstly explore Sudanese consumers' perception and acquaintance with onion commodity, and their motives for buying the commodity and using it. Secondly to reveal users insights and views on the proposed new products and the attributes that consumers like a new onion product to possess. Thirdly is to investigate consumers' willingness to buy a new product and their requirements. Data is collected using Focus Group Discussion technique. Collected data are discussed and analyzed using frequency test based on what respondents expressed their views, attitudes and their expectations on the processed onion product. The research was concluded by highlighting implications on suppliers of potential product to develop their marketing policy based on the marketing mix concept (4 P's).
\end{abstract}

Keywords: Consumer preference; Explorative research; Products attributes; Focused group discussion; 4P's

\section{Introduction}

Decision on investment in Sudanese manufacturing sector is usually supply driven and mostly influenced by resource based analysis. It is not common that manufacturers design product upon consumers' opinions. Whereas demand driven decisions signify the marketing orientation that food manufacturing firm should keep to, and that managers are aware that surviving market competition depends largely on how customers perceive the value a food company is providing to them. Sudanese household and the tourism enterprises such as restaurants, cafeterias and hotels are the main conventional consumers of food products such as vegetables. While restaurants compete to offer ready food service that match customer tastes yet household is where taste for food and perception on quality are created and get established as habitual issue. These food habits developed as an outcome of interaction of several environmental factors. Atkin sees food habits formation when cheap abundant agricultural goods induce adults to purchase large quantities [1]. Children are fed these locally abundant foods, and develop particular tastes for them in adulthood. Over many generations bias in household consumption emerges as habit. And households will choose to purchase the familiar local foods that they know how to transform into high-quality meals. Differently Caswell argues that consumers' perception of quality is influenced by the product's intrinsic attributes as well as by extrinsic indicators and cues provided by the seller of the product.

Sudanese consumers develop their own preferences on the variant food products based on local economic, cultural, and ecological conditions. And therefore they place preference for the attributes they have conceived as best satisfying their shopping goals and requirement. Sellers in their effort to achieve customer satisfaction and to maintain the competitive share in market they corresponds to consumer perception on product qualities.

This research looked on food product characteristics that define it in both states of search and experience. As per [2] Nelson a good is identified as a search good when consumers can evaluate relevant attributes information before the purchase (e.g., price, dimension, size, color), while it is defined as an experience good when relevant attributes information can be determined only after consumption (e.g. experiential eating quality such as taste and convenience). Characteristics that relate to credence goods are not sought by the research for many reasons that are explained by level of citizenship development and awareness that shape the perception of consumers in developing countries on goods qualities. The credence good category incorporates a wide range of fairly intangible and often interrelated characteristics such as outcomes related to environmental, ethical, social and human rights, etc. that may fully or partially fall under the realm of public goods [3].

\section{Research problem}

The importance of consumers' preferences for products and service providers is that consumers are those who are doing the purchases of products and services offered for sale and their preferences comprise a basic element of demand function. Satisfaction is associated with the value attached to the product attributes that consumers perceive. The research problem is concerned with investigating whether consumers demand for processed onion is influenced by attributes that they assign for the product and whether consumers can identify these attributes.

This research on consumer preferences for onion products is carried out to explore attributes that Sudanese consumers ascribe to the onion product and to highlight the implications of that preference on producers' marketing policy. The research focus is to generate information about attributes that consumer household would like to find in the onion products they consume. The investigation span the different states of product utilization from the point of view of middle income household like raw state, semi prepared or ready prepared product as expressed by the research respondents [4].

\section{Research questions and research variables}

In quest of explanation to our research problem four main questions are developed as follows: What does the product (onion) mean to the consumer household: In this section researcher focus is on knowledge about onion that users have, their acquaintance with

${ }^{*}$ Corresponding author: Nadia Hassan Sidahmed Hassan, Industrial Research and Consultancy Centre, Khartoum, Sudan, Tel: +249 911449106; E-mail: nadiahsh@yahoo.co.uk

Received July 21, 2015; Accepted July 27, 2015; Published July 31, 2015

Citation: Hassan NHS (2015) Consumer Preference Implications on Onion Suppliers. Int J Econ Manag Sci 4: 281. doi:10.4172/21626359.1000281

Copyright: ( 2015 Hassan NHS. This is an open-access article distributed unde the terms of the Creative Commons Attribution License, which permits unrestricted use, distribution, and reproduction in any medium, provided the original author and source are credited. 
the product, and what does onion commodity represent to them i.e. its importance and value.

Second question is about users experience with the product (onion): In this section of the enquiry, researcher tackled the user's handling, relationship and feeling (attitude) towards the product under study [5].

Third question concerns the attributes that onion users prefer. The aim of discussion in this section is to identify the attributes that onion attach to product and how they perceive the offering of onion products in the market should meet these attributes.

Fourth research question tackles the response and reaction of consumers to introduction of the processed onion products to market [6].

\section{Definition of research variables}

Primary Research variables are stemmed from research questions and are further extended into relevant research variables by respondents as they elaborated in their answers to the above questions, other relevant issues are also raised by group of discussion and included in the analysis.

The main research variables that extracted from the main research question are formulated by the researcher and were casted in the questionnaire administered by the moderator. Respondents reacting to questions were further developing these main research variables into detailed variables (Table 1).

\section{Paper structure}

The paper is divided into three parts following this introduction. The first part describes methodology adopted for collecting data and the analytical method used, followed by a Findings and Discussion summary of important attributes of consumers for onion product as inferred from consumers' response [7]. The third part concludes by drawing implications for food industry managers as concern their marketing policy.

\section{Part 1: Research Methodology}

Focus groups discussion, FGD is selected as the technique to generate data. Focus groups are seen as valuable tools for exploring how points of view are constructed as well as how they are expressed.

The goal in organizing focus groups is to investigate concerns, experiences, attitudes or beliefs related to a clearly defined topic. As a qualitative research method FGD addresses research questions that require depth of understanding that cannot be achieved through quantitative methods. It is agreed upon its usefulness in exploratory research and its strength originate from its capacity to provide concentrated amounts of rich data, in participants' own words, on

\begin{tabular}{|c|c|c|}
\hline Research question & Main variables & Detailed variables \\
\hline \multirow{3}{*}{$\begin{array}{l}\text { Question 1: } \\
\text { (What does onion mean to you and how you define your } \\
\text { consumption behavior }\end{array}$} & Importance of onion & $\begin{array}{l}\text { Using onion } \\
\text { Perceived value }\end{array}$ \\
\hline & User self-definition in relation to product & $\begin{array}{l}\text { Intensity of consumption } \\
\text { Knowledge about product } \\
\text { Handling modes }\end{array}$ \\
\hline & Psychological relationship & $\begin{array}{l}\text { Affinity } \\
\text { Sentiment } \\
\text { Food security } \\
\text { Emphasis on availability of product }\end{array}$ \\
\hline \multirow[b]{2}{*}{ Question 2: (Your experience with raw onion) } & Handling of raw onion & $\begin{array}{l}\text { After purchase treatment: sorting, storing } \\
\text { Precooking processes }\end{array}$ \\
\hline & Attitude for dealing with onion & $\begin{array}{l}\text { Sentiment s: enjoyment versus annoyance. } \\
\text { Adaptation to product } \\
\text { Negativity avoidance tactics } \\
\text { Willingness to avail time to raw onion } \\
\text { Tendency towards switching to substitutes. }\end{array}$ \\
\hline \multirow{3}{*}{ Question 3: what do like to find in onion product } & Product basic characteristics & $\begin{array}{l}\text { Product state/ freshness, nutritional value, } \\
\text { sensory characteristics color/odor taste }\end{array}$ \\
\hline & Economic considerations & $\begin{array}{l}\text { Price, } \\
\text { Availability, } \\
\text { Time saving, } \\
\text { Storage period, } \\
\text { Differentiation, and substitutes, } \\
\text { Form of processed }\end{array}$ \\
\hline & Behavioral & $\begin{array}{l}\text { Safety, } \\
\text { enjoy dealing with onion } \\
\text { Labor requirement }\end{array}$ \\
\hline \multirow{3}{*}{ Question 4 : response to introduction of processed onion } & Crucial attributes & $\begin{array}{l}\text { Nutritional value } \\
\text { Preserving product basic characteristics } \\
\text { State/ freshness, } \\
\text { Level of processing } \\
\text { Packaging } \\
\text { Pricing }\end{array}$ \\
\hline & Uncertainties & $\begin{array}{l}\text { Safety, } \\
\text { Loss of taste, } \\
\text { Effect of storage on quality, } \\
\text { Availability }\end{array}$ \\
\hline & Willingness to buy the new processed onion product & $\begin{array}{l}\text { Seasonality of demand } \\
\text { Willingness to try } \\
\text { Willingness to replace the conventional product }\end{array}$ \\
\hline
\end{tabular}

Table 1: Research variables. 
precisely the topic of interest. Interaction of participants adds richness to the data that may be missed in individual interviews [8].

Target population chosen in this study is the urban middle income households' stratum because factors that comprise demand for the product under study are mainly attributed to conditions typical to the case of urban middle income households. Questions addressed are designed to involve gathering opinions and impressions from respondent' consumer housewives. The basic tool is a questionnaire administered by the researcher (moderator). Group discussions help respondents to be frank and open. Two groups composed of 11 ladies each were actively participating in four discussion sessions [9]. Discussion was organized in two separate sessions per group to tackle two questions in each session, the moderator was the chief researcher aided by two persons to help in recording and writing note and in organizing the meeting. Full attendance (11 women each) was achieved for the two morning sessions but also few missing participants (2-3) are witnessed in the midday sessions. Participants were very collaborative and enthusiastic. Moderator provided an environment for openly and freely respondents expressed their opinions that the research didn't experience missing values, discussion was administered in a circle sitting where every participant got the chance to respond verbally.

\section{Selecting participants}

Due to limited resources the study relies on purposive sampling where sample formation is based on the eligibility of participants to represent target population characteristic i.e. middle income household in Khartoum area. Considering that the study itself is of a typical case mode and that the type of information sought is of general or common practice experienced by mostly every housewife in moderate family of Sudanese society.

The researcher went for membership list way for recruiting participants, applying the process of gathering the group together in the same place at the similar time. Sample is selected from list of female employees in the Industrial Research and Consultancy Centre [10]. This approach provides for good degree of familiarity intended to enhance free and relaxed group discussion. The researcher herself was the contact who knew the target group. Although researcher preferred a homogeneous group from same range of income strata other considerations include demographics and economic factors are also attended to, such as age, education and residence location. In conducting the focus group technique it was stressed that the sample reflects the target population that hold some diversification in terms of education, age, residence location and household size. Group selection method insured that the sample provides a cross section of the larger layer of middle working women i.e. from different scales of middle positions and salary. Yet this diversification is not wide enough to break the boundary of middle income stratum.

Despite limitations of the Focus group discussion method as regards generalization, the results it generates (data) are applicable to the social stratum represented by the selected sample that had been included in the discussion group. This is due to group similarity in social and economic factors [11]. Other practical limitation of FGD is that when participants are making free expression on answering the research questions they tell a much relevant but also a much irrelevant answers that researcher had additional job effort of filtering.

\section{Research design}

The group discussion was arranged to tackle the five main questions administered over four sessions, consequently findings and results constituted five distinct sections as follows.

Session One (morning): Importance of onion

Session Two (morning): Experience with onion

Session three (midday): Onion Attributes

Session four (midday): Response to introduction of new onion products

\section{Part 2: Findings and Discussion}

This part tackles presentation of the data collected from responses of the group discussion and centered on the research main questions that are: importance of onion, experience with onion, Onion Attributes and response to introduction of new product to the market.

\section{Section one: Importance of onion}

This section tackles responses to question 1; what does onion mean to you?

Focus is on knowledge about onion that onion users have, their acquaintance with the product, and what does onion commodity represents to them i.e. its importance and value, responses to the question elaborated in Table 2 and were as follows.

All respondents are using onion in varied ways and $36 \%$ of them express themselves as high consumers.

$82 \%$ of respondents described onion as basic food ingredient, nutritious, important for giving a taste for food.

$36 \%$ of respondents stressed importance of the product availability.

$32 \%$ of respondents mentioned they handle onion at home in different ways of storing to cater for season of scarcity.

$23 \%$ commented on conditions of onion storage by suppliers and quality of onion. $13 \%$ stress onion availability and storage at home where $9 \%$ see storing as costly.

$14 \%$ of respondents mentioned importance of product development.

\begin{tabular}{|l|c|c|}
\hline Variable & frequency & $\%$ ratio \\
\hline Using of onion & 22 & 100 \\
\hline Varied uses & 22 & 100 \\
\hline $\begin{array}{l}\text { Basic food ingredient, nutritious, basic for taste/ flavor of } \\
\text { traditional food }\end{array}$ & 18 & 82 \\
\hline As medicinal element & 4 & 18 \\
\hline Onion is food security indicator (psychological notion) & 2 & 9 \\
\hline A source of cost for home storage and processing & 2 & 9 \\
\hline Prefer buying traditional prepared dry onion & 1 & 5 \\
\hline Emphasis on a constant availability at home & 8 & 36 \\
\hline Knowledge on storage of fresh onion & 2 & 9 \\
\hline Awareness on quality of stored onion & 5 & 23 \\
\hline High consumer & 8 & 36 \\
\hline $\begin{array}{l}\text { Home processer (drying, frying, frozen onion for season of } \\
\text { scarcity) }\end{array}$ & 7 & 32 \\
\hline Product developer & 3 & 14 \\
\hline $\begin{array}{l}\text { Emphasis on freshness and onion characteristics (taste and } \\
\text { odor) }\end{array}$ & 6 & 27 \\
\hline
\end{tabular}

Responses to question1 (What does onion mean to you and how you define your consumption behavior)

Number of respondents: 22

Table 2: Importance of onion. 
27\% value Freshness and natural onion characteristics (taste, texture and odor) especially in salad.

$18 \%$ mentioned importance of onion as medicine. Some respondents see it as indicator for food security. These finding are portrayed in Figure 1 below. Frequency expressed as percentage of total cases that reached 22 respondents.

\section{Section two: Experience with onion}

Main question: Experience with onion.

This section circled around the research main question: Experience with onion.

In this section of the enquiry, researcher tackled the user relationship and feeling (attitude) to onion. Respondents were asked to describe their experience with onion product, and to express this relationship in terms of behavior, feeling and attitude when they get in contact with onion. Referring to Table 3 respondents mentioned six common processes that done in dealing with onion starting from purchasing, sorting, storing, peeling, cutting and cooking.

$50 \%$ of respondents do the job of quality sorting and sorting for diff uses then storing.
$82 \%$ of respondents are dealing with onion precooking preparation processes such as peeling and cutting.

But annoyance and negative attitude when dealing with onion (preparation, cooking, storing) was expressed by $77 \%$ of respondents where $64 \%$ of discussion group members consider onion preparation and cooking as time consuming. Some consumers developed different tactics to avoid the displeasure in dealing with the product such as referring to another practice to avoid odor and tears such as soaking in salted water before cutting or divert job to another person or use tool, deal with it with caution, buying dry onion or get adapted to odor.

$18 \%$ of respondents expressed positive attitude to dealing with onion (storing, preparing and cooking). They stated that they deal with onion in good mode, enjoy peeling and cutting onion and can manage time to mitigate inconvenience due to time consumed by onion preparation.

$5 \%$ of the group said they can avail time to prepare onion and they are not bothered by odor or by preparation lengthy period [12]. Moreover, they provide good care for stored onion because they consider its importance to them. The same group described themselves as high consumers of onion.

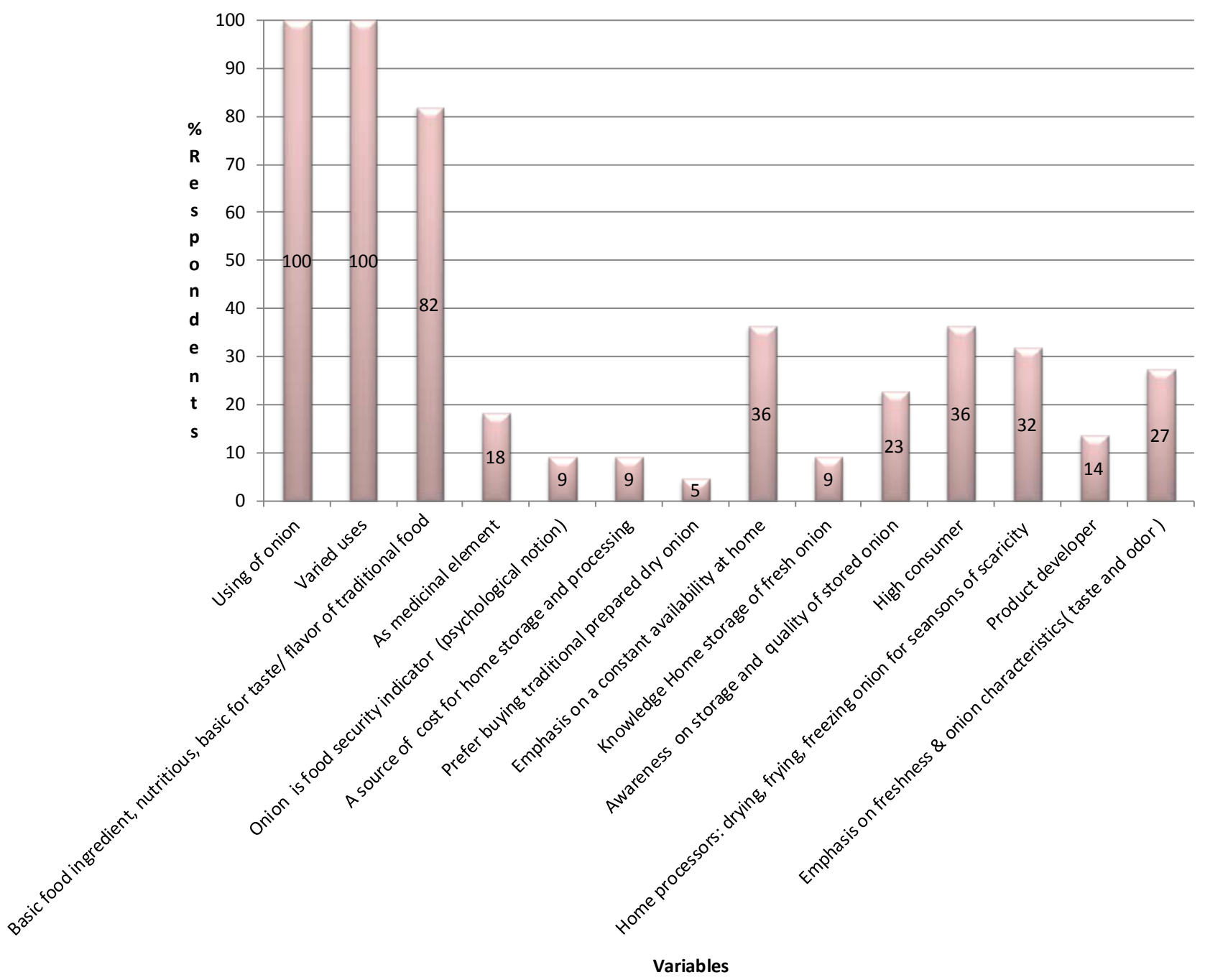

Figure 1: Importance of onion to users. 
$5 \%$ of respondents are indifferent dealing with onion, they see it a routine job.

Emphasis in freshness with the associated odor and tears appear to justify tolerance for inconveniences during preparation as compromise. The above results are portrayed in below Figure 2 .

\section{Section three: Wanted onion attributes}

Main question: Attributes users wish the onion product to have.

The aim of discussion in this section is to identify the attributes that onion users attached to the onion product and how they expect the characteristics of any onion product in the market meets these attributes. Respondents expressed their expectations on the onion product that they wish suppliers provide to market. These expressions were linked to the previous question about consumers' experience with onion [13]. They were able to recognize the pros and cons in dealing with the commodity; they spot the elements that they prefer and the elements that they wish to be eliminated. These attributes as shown in Table 4 can be summarized as follows:

$58 \%$ of respondents stressed maintaining the nutritional content and the natural characteristics of onion and preferring buying fresh onion at the time of availability at season. $32 \%$ emphasized on freshness and onion characteristics (taste and nutrition) even in the off season.

$26 \%$ of respondents wanted the fresh product to be peeled, cut and prepared as ready to cook. Some wanted further processing prepared as fried or dried.

$21 \%$ of respondents mention safety of user as regard the product quality.

$37 \%$ of respondents expressed their hope to save time they spend in preparing onion. Requirements such as availability of product all the year; durability and shelf life; reasonable price, sparing onion storage labor and annoyance are expressed by relatively smaller fraction ( $4 \%$ $5 \%$ ) of the respondents group.

$10 \%$ prefer onion as dry form.

$74 \%$ of respondents emphasized use of red onion for cooking and white for salads (21\% prefer a product that helps to escape odor problem i.e. to have product with less remaining odor in hand [14]. Few mentioned the issue of tears; they were also some suggestions for solving odor and tears problem. The above attributes are portrayed in Figure 3 below.

\section{Section four: Response to introduction of new onion products}

Respondents were asked whether and how they will respond to introduction of new onion products that are peeled and packed in variant forms: fresh peeled whole ball, fresh peeled and chopped onion, chopped and fried or chopped and dried. Referring to Table 5 responses to the main question on how they will receive the new onion products can be elaborated as follows:

$88 \%$ of respondents were willing to buy and try the new products under conditions that.

$63 \%$ of respondents stressed that new offerings maintain the whole nutritional value that traditional onion product possesses. While $13 \%$ of respondents want it to be easy handling.

$50 \%$ emphasizes freshness and prefer peeled and cut semi prepared onion.

$25 \%$ as maintain onion characteristics: taste, texture, cooking performance, etc.
Sensitivity to product extrinsic aspect such as price was alarmed by more than one third of respondents. A further consideration related to the buyer income is the pack size was expressed by $50 \%$ of respondents that peeled or prepared products are to be packed in what they described as varied but mostly important economic package [15]. This attribute cater for income level and frequent purchases to avoid longer keeping period. Uncertainty is expressed by the focus group as:

$31 \%$ of respondents mentioning risk of contamination and uncertainty about safety of packed onion. (in comparison to question 3 where the worry about safety was not high as users is referring to her experience with traditional product but when it comes to the proposed processed product her worry increased because it involves further external element).

$6 \%$ were uncertain about taste and performance of industrially prepared onion especially the onion that stored in frozen form. The performance that pertains to time of cooking and softening of cooked onion.

\begin{tabular}{|c|c|c|}
\hline Variables & frequency & $\%$ ratio \\
\hline \multicolumn{3}{|l|}{ After purchase treatment } \\
\hline quality sorting and sorting for diff uses then storing & 11 & 50 \\
\hline $\begin{array}{l}\text { Care for stored onion (Frequent check to ensure good } \\
\text { aeration ) }\end{array}$ & 4 & 18 \\
\hline Precooking preparation & 18 & 82 \\
\hline \multicolumn{3}{|l|}{ Attitude } \\
\hline Enjoy shopping fresh onion & 1 & 05 \\
\hline $\begin{array}{l}\text { Enjoy preparing onion( dealing with onion in good mode and } \\
\text { can manage time) }\end{array}$ & 5 & 23 \\
\hline Annoyance with onion storing, peeling, cutting .... & 19 & 86 \\
\hline Adapt to odor, not annoyed & 2 & 09 \\
\hline Indifferent in dealing with onion & 1 & 05 \\
\hline Willing to avail time preparing fresh onion & 2 & 50 \\
\hline Onion preparation and cooking is time consuming & 14 & 18 \\
\hline \multicolumn{3}{|l|}{ Tactics } \\
\hline Deal with onion with caution & 3 & 14 \\
\hline Change to another practice to avoid odor and tears & 2 & 09 \\
\hline Divert cutting job to another person or use tool & 6 & 27 \\
\hline Prefer buying sun dry onion & 1 & 82 \\
\hline
\end{tabular}

Responses to question 2 (Your experience with raw onion) Number of respondents: 22

Table 3: Experience with Onion.

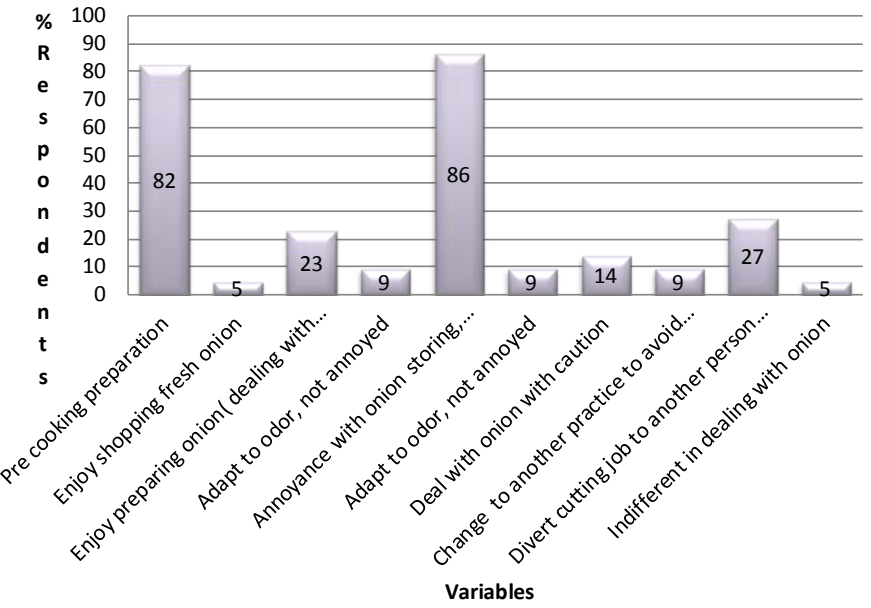

Figure 2: Experience with onion. 
$31 \%$ of respondents are conservative on storage period as conceived to negatively affect onion quality they want it to be as short as possible.

On average 59\% of respondents purchases of traditional onion are expected to be replaced by the new products considering users' demand is met (Figure 4).

\section{Part Three: Discussion and Implications}

Discussion: A product is defined in terms of its features and benefits and consumers make decisions by allocating income across the different goods offered for sale in order to obtain the greatest benefits from consuming the goods they have selected. Their decisions are related to their subjective tastes which define their preferences. In turn Consumer preference is associated with the satisfaction that he/ she derives from consuming a product- in other words consuming the product features [16]. This is what explains demand is a function of how consumers behave. Marketers draw distinction between product features and product benefits. While the features of a product are more objective and are formed by the intrinsic physical characteristics or qualities of a product such as shapes, size color, odor, perishability, seasonality etc., and the extrinsic characteristics such as economic and geographical association. Benefits on the other hand are subjective because it is dependent on the product features as well as on how these features are valued by the users and perceived to satisfy their needs. Consumers acquaintance with the product help them develop somehow stable preferences to the qualities that they perceive giving them the greater satisfaction from consuming it , and the presence of these perceived qualities in the product offered for sale will entice them to purchase it.

A significant market share for a new product could be formed by consumers who are looking for a change that incorporates the favorable features they like and sparing them the unfavorable [17]. Focused group discussion method applied to collect data in this research was effective to provide for free opinions expression that yielded the particulars that onion as natural product is of importance and use on daily basis. As inferred from the above research data Sudanese consumers have varied their ways and purposes for using onion, majority of users describe it as food item and value the nutritious and sensory characteristics and to a lesser extent some value its medicinal qualities. Historic existence of the product in the Sudanese household food collections led to development of an emotional relationship that exceeds characterizing the recipe of conventional dishes to a security notion. Despite this long experience and knowledge on handling onion product, its preparation and storing remain a source of inconvenience for users [18]. The attitude to handling the product being positive or negative is mainly derived from the personal experience that a consumer has when dealing with the onion. On the other hand consumers show considerable emphasis on availability of the product based on the importance they assign to its use. Also respondents put highest relative importance on freshness; basic sensory characteristics, ease of handling and, to a lesser degree, on price. Despite the high importance attached to the commodity but negative attitude described as annoyance, time consuming is associated with its preparation process before cooking. Even some developed tactics by which the negative characteristics they experienced with the raw onion will be turned into positive qualities by changing or avoiding.

Based on their consuming experiences respondents were able to identify the characteristics and qualities that will make the potential product eligible for bringing them the maximum satisfaction. Research respondents go further to link their choice for the new processed product with extrinsic features such as availability which they rank as important. They stress availability is related to choice and switching propensity to substitute. It is normal that when shoppers can't buy the product because it is not available then they are induced to make an alternative choice [19]. Onion product availability has critical importance for Sudanese households who assign psychological notion of food security to continual presence of onion in their home stores despite the annoyance caused by that process of storage. Yet if removal of home storage headache by the new processed product is not brought together with its availability in retailer shelves then propensity to switch back to traditional raw product will be higher.

Hence onion products' supplier is to pay attention for distribution management to avoid the misaligned incentives between upstream and downstream firms in the choice of which products to carry. As per C. T. Colon et al product removals result in lower revenues for upstream manufacturers but higher profits for the downstream vending operator when consumers substitute to products with lower wholesale costs.

Implications on supplier: The above attributes that are defined by respondents comprise the quality aspect of demand for onion products users. These are expressed as symbolic for what consumer like or do not like or what they expect to see in the new product which in turn connote implications on product supplier. Suppliers of the proposed onion products are to develop their marketing policies with aim to provide customer satisfaction. Reaction to the consumers' demands revealed by the market research- like this consumer preference investigation- can be translated in marketing policies based on the marketing mix concept or what is defined as (4P's). Marketing mix" describes the choices or decisions organizations have to make in the whole process of bringing a product or service to market. It was first expressed in 1960 by E J McCarthy to be composed by four elements (4P's) (Figure 5).
a. Product (or Service).
b. Place.
c. Price.

d. Promotion.

While marketing policy is suggested for each of the P's referring

\begin{tabular}{|l|c|c|}
\hline Variable & frequency & $\%$ ratio \\
\hline Product basic features & 11 & 58 \\
\hline Freshness in time of availability & 6 & 27 \\
\hline $\begin{array}{l}\text { Emphasis on freshness and onion characteristics (taste } \\
\text { and odor) even in off season }\end{array}$ & 11 & 58 \\
\hline Quality and nutritional content & 14 & 74 \\
\hline Red onion is preferred for cooking, white onion for salad & 1 & 05 \\
\hline Storable & 1 & 05 \\
\hline limited shelf life & & \\
\hline Economic factors & 5 & 26 \\
\hline Type of processed: peeled/prepared/ fried, or dried & 3 & 16 \\
\hline Sensitivity to price & 7 & 37 \\
\hline Convenient/time saving & 1 & 05 \\
\hline Availability of processed & 2 & 11 \\
\hline Other onion products (juice, oil) & 4 & 21 \\
\hline Onion with no odor/escape odor problem & 1 & 52 \\
\hline Onion with no tear & 4 & 21 \\
\hline Safety & 1 & 05 \\
\hline Less labor in storage & 1 & 05 \\
\hline Enjoyment in dealing with processed onion & & \\
\hline
\end{tabular}

Responses to question3 (Attributes that you like in any Onion product) Number of respondents: 19

Table 4: Wanted attributes 


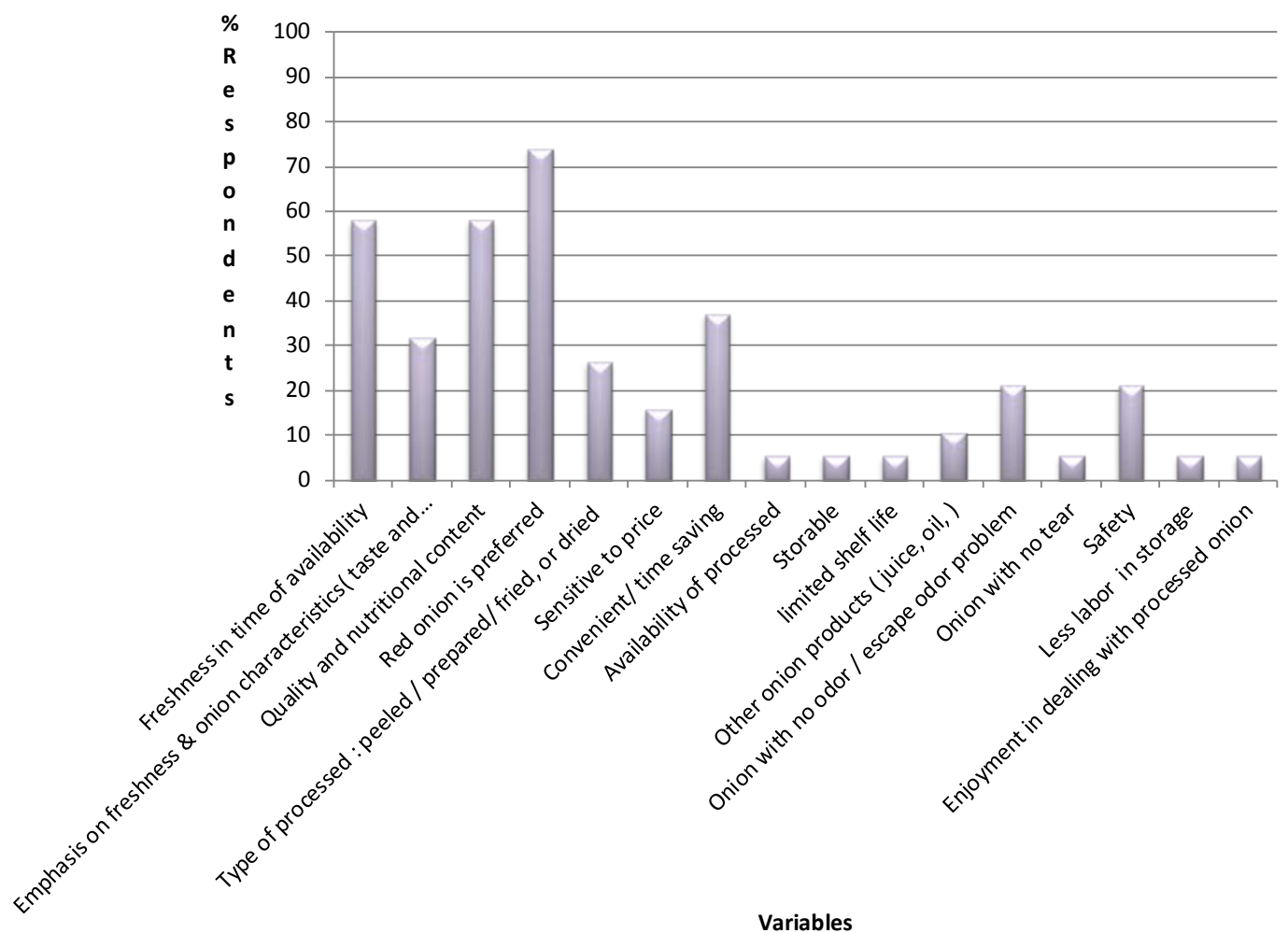

Figure 3: Preferred attributes in any onion product.

\begin{tabular}{|c|c|c|}
\hline Variable & Frequency & $\%$ \\
\hline \multicolumn{3}{|l|}{ Requirements (attributes crucial for consumers) } \\
\hline Maintain whole nutritional value & 10 & 63 \\
\hline Freshness & 8 & 50 \\
\hline Prefer Peeled/semi prepared & 8 & 50 \\
\hline Maintain onion taste & 4 & 25 \\
\hline Impact of freezing on cooking time & 1 & 6 \\
\hline Easy handling & 2 & 13 \\
\hline Varied but economic package & 1 & 6 \\
\hline Reasonable price & 6 & 38 \\
\hline \multicolumn{3}{|l|}{ Uncertainty } \\
\hline Risk of contamination, uncertainty about safety & 5 & 31 \\
\hline $\begin{array}{l}\text { Uncertainty about taste \& performance especially frozen } \\
\text { onion }\end{array}$ & 1 & 6 \\
\hline Effect of storage period on quality (require short period) & 5 & 31 \\
\hline Risk of unavailability & 3 & 19 \\
\hline \multicolumn{3}{|l|}{ Willingness to accept new processed onion } \\
\hline Willing to accept new products any time & 5 & 31 \\
\hline Accept only dry onion at offseason & 2 & 13 \\
\hline Willing to accept new products only at off season & 2 & 13 \\
\hline Willingness to try new products & 14 & 88 \\
\hline Willing to replace new processed for traditional onion & 13 & 81 \\
\hline
\end{tabular}

Responses to question 4 (How will you respond to introduction of new processed onion product)

Number of Respondents 16 .

Table 5: Introducing new product. to what respondents have mentioned, a link is made to other mix components so as to insure that the four Ps need to be considered in relation to each other. Elaborated as follows.

a. Product: For suppliers of the proposed onion product to make proper marketing strategy, attending to how consumers perceive attributes of the product would make a good guide to the design of the product.

Respondents representing the wider population of onion users in urban Sudan value natural characteristics and therefore refrain from products that contain preservatives and additives. They associate nutritional value and sensory characteristics with freshness. They highly stress on the nutritional and sensory features at different processing level and types. It is therefore entailed on suppliers to ensure freshness qualities, keep natural characteristics of onion such as taste, texture, and flavor and maintain the nutritional content and health benefits that users believe they get from onion. Semi Processed product (peeled and cut) would maintain these qualities and maintain freshness. Yet further processed product such as dried, fried or frozen should be designed to ensure its inclusion for the other preferred qualities and exclusion of non-wanted qualities. Characteristics of the new product should be providing solution for source of annoyance that's odor, and would spare consumer effort of peeling, cutting and even storing. This require that suppliers formulate product profile in such a way that beside full processed onion is to include semi processed in terms of peeled and cut so as to satisfy demand for freshness, a further survey to determine volume of demand for each product offering and thus quantities of different offerings will be needed.

Supplier should note that Demand for different onion products varies with seasons where dried or fried onion products are traditionally associated with religious occasions such as the month of fasting 


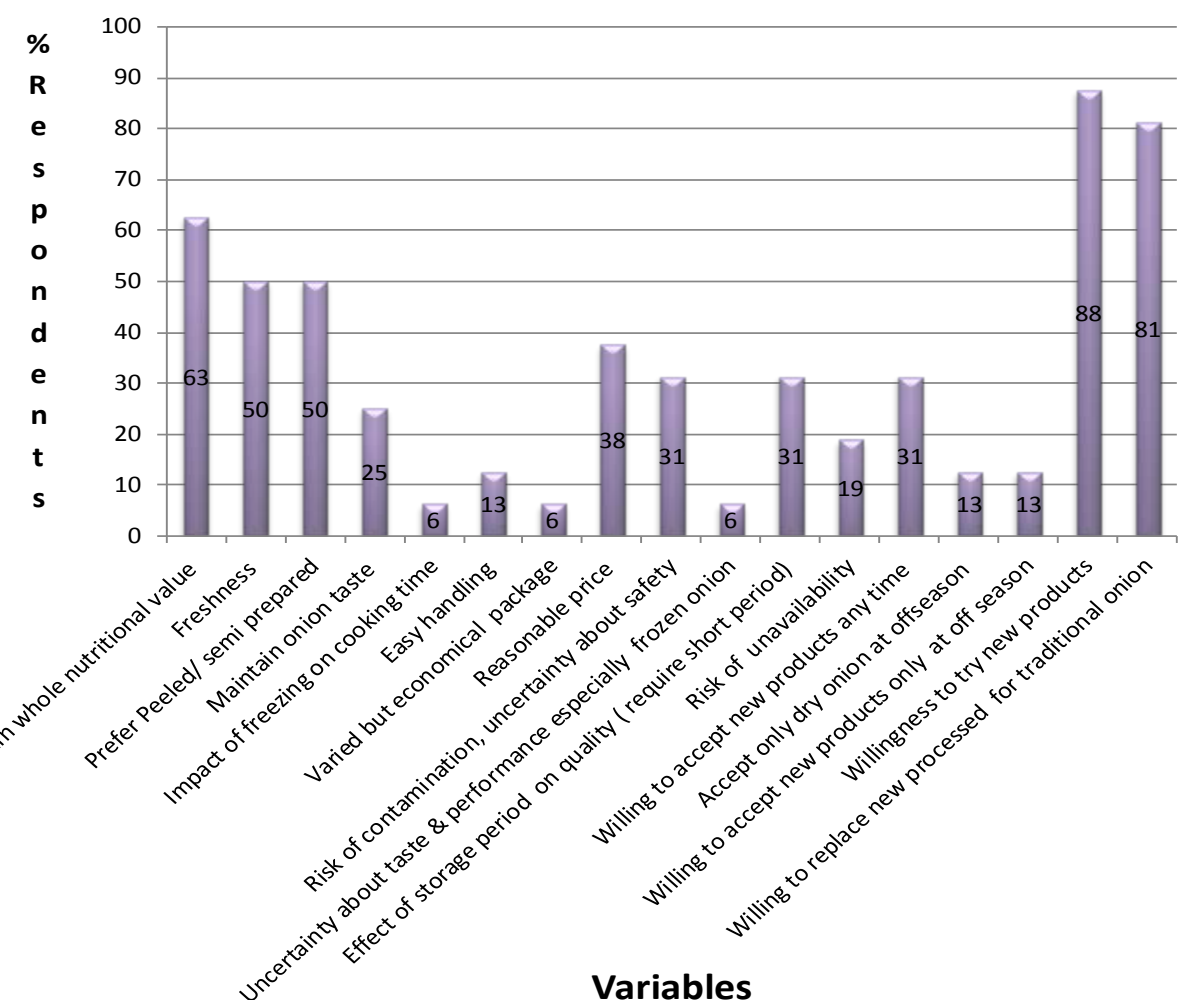

Figure 4: Users Response to Introduction of New Onion Products.

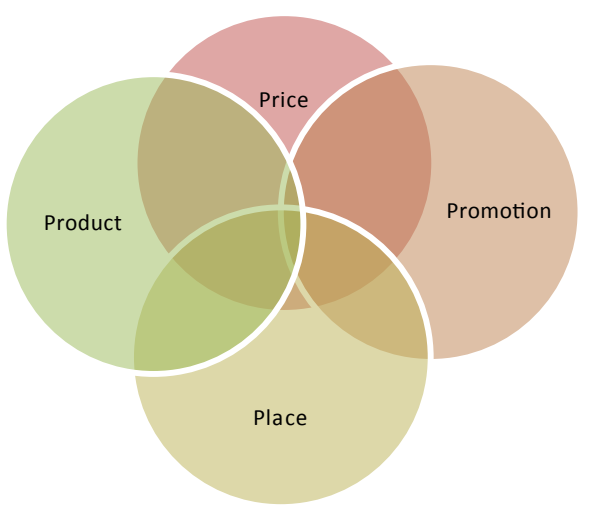

Figure 5: Interrelated marking mix.

(Ramadan) and with family occasions. Here freshness is traded for time saving and convenience and even higher scale of processing such as full cooked onions would also be demanded. Supplier is to ensure that new products offer the same value that traditional onion does in terms of food enjoyment, sense of food security. At this point a connection to other P's particularly place and distribution is to be planned so as to grantee availability. Packaging is an important factor supplier has to cater for; it is an element for appealing and provides for food safety and maintains freshness and other preferred qualities. Packs are to be sized in order to suit the purchasing power of targeted income group of household consumers and also to meet large purchases made by business.
Producers to satisfy requirement for safety should abide to specification of safety and health regulations and maintain labeling information, Product information that put in label meets a crucial demand that users place on supplier. Such as information about shelf life, storing requirement, storage period, expiry etc.

Although considerable portion of respondents emphasize product natural features over economic aspects, but it is acceptable to classify the new onion product as basic product because majority of middle income Sudanese households are price-conscious. However paying attention to services, warranties, and brand name will be more addressing needs of business demand such as retailers, restaurants and hotels. These further attributes beside the physical product define the product as of bundle of goods and services. Supplier's product bundle should meet the identifiable needs of a particular target market. Of course the competitive strategy of supplier organization should go for differentiation versus its competitors.

b. Place: To design distribution strategy supplier has to consider where buyers look for the product. Different modes of distribution suit different types of purchases. Conventionally retailers and groceries are places for household shopping plus occasional exhibitions and the weekly open markets. Suppliers to decide using other distribution modes such as direct or online selling depend on his/her assessment to the development undergone in $\mathrm{B} 2 \mathrm{~B}$ dealings and on cost of transactions, but also depends on sale force that producer use.

As inferred from research data product availability is a critical feature that respondents stress. Marketers observe the correlation between product availability and purchase intention. Literature includes different opinions about distribution or place strategies for enhancing or reducing product availability as a tool to trigger purchase intention. 
Distribution operation has the direct impact on shortages or failures of supply. Respondents stressed that availability of the commodity is an important issue to the extent that some links it to psychological notion of security but they mention availability assurance put the burden of home storage on them. Because the new products must be offering solution for sparing users that inconvenience, availability should be assured through selection of proper distribution channels.

Thus importance of Place is expressed by the requirement for product availability and also by demand for removal of annoyance with shopping and carrying bulky raw onion. Though small fraction of respondents draws attention to this problem, but it is well known that making good availability of the product is a graceful approach for attraction and creation of demand.

Retailer decision on what to be on shelves is affecting distribution strategy of onion producers, balancing interests is a critical issue to be attended Feasibility for such investment is backed by supply side elements that assure continual availability of adequate quantities of product on retailer shelves at the right time otherwise shoppers will be switching to an alternative. Then proper value chain management; coordination and utilizing distribution strategy are needed to overcome problem of shortage and availability. On the other hand Supplier is to balance promotional generated demand and the requirement for real on-shelf availability i.e. supply is not to get short of demand.

c. Price: Price reflects the value of the product or service to the buyer who sees it as one part of the cost to gain satisfaction. It's a tool for balancing features against value. The Pricing for the proposed new product is to be done considering the users sensitivity to difference in price compared to the competitor traditional onion. Considerable part of respondents mention sensitivity to price and thus probability to switching to substitutes, And as aforementioned the target market is a segment of middle income household that are used to plan their consumption budget including expenditure on food. Here supplier is to consider what is the most it can cost to produce, and still be sold satisfactorily profitably. Deciding on price salespersons are to investigate when the small decrease in price would gain extra market share and when will a small increase gain extra profit margin.

Considering competition supplier for new product can start with competitive price but most important that - in the long term cannot rely strictly on price to compete because these forms of competition are volatile. Further decisions are on amount of discounts to be offered to trade customers or to large purchases.

d. Promotion: From the variant modes of communication onion suppliers should decide on the widest reaching means for their target audiences. In Sudan as well as in other developing countries food companies prefer reaching their audiences by advertising in TV more than via the other communication means. Producers also use live demonstration in events like exhibition and other gathering. On the other hand Sudanese household used to react to TV and radio ads more than other means such as press, the Internet or direct marketing. In a more advanced marketing level "interactive" advertising via internet or phone enables supplier to listen to consumer wants and opinions. Yet such mode will be chosen depending on the response of target audiences; on balancing cost and profits and on the intensity of competition that influence choice of promotional activity and the need for differentiation. On the time of market launch different means would be utilized in an intensive promotion campaign but when new product get established in the consumer basket then promotion effort will be normalized. Subsequent promotions would be timed upon frequent market research findings.
Communication message is to address critical issues raised by respondents as worries and uncertainties about safety, packaging specifications and product shelf life. Moreover, promotional efforts should be designed to communicate products qualities and benefits to consumers. Advertisement designed a way that portrays new product as solution for worries of scarcity and highlights the value of sparing consumers the nuisance of storing, cutting, tears and odor. Promotion message also should invest on qualities of time saving and convenience that new onion products provide. Promotion must be aligned with distribution effort to ensure availability that consumer values and would draw attention to the burden of storage is then removed and born by the supplier. Respondents describe their pattern of demand for onion commodity by Sudanese household is a daily subject; exclusively they describe it as basic food ingredient. Therefore promotion effort will be slimed or sent to break is dependent on the market share and on as far as advertisement budget is not shaking the targeted profits. Deciding on the best time to highly promote or to intensify ads depends on seasonality in the market. As mentioned above higher demand is expected seasonally.

\section{References}

1. Atkin, David (2013) Trade, tastes, and nutrition in India. American Economic Review 103: 1629-1663.

2. Nelson P (1970) Information and consumer behavior. Journal of Political Economy 78: 311-329.

3. Riccarda M, Roberta R, Dawn TM (2011) Consumer preferences for fruit and vegetables with credence-based Attributes: A review. International Food and Agribusiness Management Review 14: 121-142.

4. Morgan DL (1993) Successful focus groups: Advancing the state of the art. Newbury Park CA: Sage.

5. Greenbaum TL (1993) The Handbook for Focus Group Research. New York: Macmillan.

6. Hicks JR (1946) Value and capital: An Inquiry into Some Fundamental Principles of Economic Theory (2ndedn), Oxford: Clarendon Press.

7. Jacoby J (2002) Stimulus-organism-response reconsidered: An evolutionary step in modeling (Consumer) Behavior. Journal of Consumer Psychology 12 $51-57$.

8. Kothari CR (1997) "Research methodology". (2ndedn), New Age Internationa Publisher, Jaipur, India.

9. Kotler, Philips (2008) Marketing management. (13thedn), Pearson Education Eastern Economy, Delhi, India.

10. Kotler P (2006) Marketing Management. Prentice Hall, New Delhi, India.

11. Krueger RA (2000) Focus groups: A practical guide for applied research (3rdedn), Sage Thousand Oaks, CA.

12. Nair, Suja R (2008) Consumer Behavior. Himalaya Publication.

13. Samuelson, Paul A (1947) Foundations of Economic Analysis, Cambridge Harvard University Press.

14. Riccarda M, Roberta, Dawn TMF (2011) Consumer preferences for fruit and vegetables with credence-based Attributes: A Review. International Food and Agribusiness Management Review 14: 121-142.

15. Christopher TC, Mortime JH (2010) Effects of Product Availability: Experimental Evidence.

16. Escalada M, Heong KL (2009) Focus Group Discussion.

17. Mary M, Sewell M (2000) Using Focus Groups for Evaluation.

18. Sylvia CNM, Borders LDA (2002) Use of focus groups in survey item development. The Qualitative Report.

19. Rabiee F (2004) Focus-group interview and data analysis. Proceedings of the Nutrition Society 63: 655-660. 